\title{
Denominações para a brincadeira "amarelinha" no estado de São Paulo: análise diatópica e léxico- semântica
}

DOl: http://dx.doi.org/10.21165/el.v48i2.2311

\section{Beatriz Aparecida Alencar ${ }^{1}$}

\section{Resumo}

Considerando a importância dos entretenimentos infantis na vida das pessoas e a influência que exercem na cultura e também na linguagem de um determinado grupo, este estudo busca analisar as denominações do conceito expresso na pergunta 167/ QSL do Projeto Atlas Linguístico do Brasil (ALiB): "como se chama a brincadeira em que as crianças riscam uma figura no chão, formada por quadrados numerados, jogam uma pedrinha (mímica) e vão pulando com uma perna só?" (COMITÊ NACIONAL DO PROJETO ALIB, 2001, p. 35). Para tanto, examinam-se dados geolinguísticos de 48 localidades da rede de pontos do Projeto ALiB no estado de São Paulo (SP) e cidades limítrofes com base em pressupostos teóricos da Dialetologia, da Lexicologia, da Semântica e da Etnolinguística, buscando demonstrar a inter-relação entre léxico, cultura e história social do estado de São Paulo.

Palavras-chave: dialetologia; estado de São Paulo; amarelinha; Projeto ALiB.

1 Instituto Federal de Mato Grosso do Sul (IFMS), Campo Grande, Mato Grosso do Sul, Brasil; bia83_12@hotmail.com; https://orcid.org/0000-0002-3559-6559 


\section{Denominaciones para el juego la "rayuela” en el estado de São Paulo: análisis diatópica y léxico-semántica}

\section{Resumen}

Considerando la importancia de los juguetes infantiles en la vida de las personas y la influencia que ejercen en la cultura y también en el lenguaje de un determinado grupo, este estudio busca analizar las denominaciones que nombran el concepto expreso en la pregunta 167/QSL del Proyecto Atlas Lingüístico de Brasil (ALiB): "cómo se llama el juguete en que los niños rayan un dibujo en el suelo, formado por cuadrados numerados, tiran una piedrita (mímica) y van saltando con solo una pierna?" (COMITÊ NACIONAL DO PROJETO ALIB, 2001, p. 35). Por lo tanto, se examinan datos geolingüísticos de 48 localidades de la red de puntos del Proyecto ALiB en el estado de São Paulo (SP) y ciudades limítrofes basado en los parámetros de la Dialectología, de la Lexicología, de la Semántica y de la Etnolingüística con objetivo de demostrar la interrelación entre léxico, cultura y história social del estado de São Paulo.

Palabras-clave: dialectología; estado de São Paulo; rayuela; Proyecto ALiB.

\section{Considerações iniciais}

Os entretenimentos infantis fazem parte dos costumes das populações desde antigas épocas. No Brasil, sobretudo no interior dos estados, ainda é muito comum as crianças praticarem jogos nas escolas, ruas ou praças. Esse hábito vem acompanhado, inconscientemente, do modo de executar as atividades e também de nomear as diversões, que muitas vezes se mostram diversificadas quando se considera a criatividade e a riqueza da língua portuguesa e do seu léxico. Ao tratar da "brincadeira em que as crianças riscam uma figura no chão, formada por quadrados numerados, jogam uma pedrinha (mímica) e vão pulando com uma perna só" (COMITÊ NACIONAL DO PROJETO ALIB, 2001, p. 36), verifica-se a predominância da denominação amarelinha/marelinha² para nomear a brincadeira, seguida de maré e pula-pula. Assim, este estudo tem como objetivo analisar as variantes léxicas que nomeiam a brincadeira "amarelinha", considerando o

2 Para fins de organização, ao se referir à unidade léxica amarelinha, a grafia foi indicada com destaque em itálico. Por sua vez, no que tange à brincadeira "amarelinha", sua indicação foi marcada entre aspas. 
viés diatópico e o léxico-semântico na análise de dados do estado de São Paulo e na área de controle. ${ }^{3}$

A questão selecionada compõe a área semântica dos jogos e diversões infantis do Questionário Semântico-Lexical do ALiB (Atlas Linguístico do Brasil), projeto de caráter nacional que tem como meta a produção de um atlas linguístico nacional. Neste estudo, foram examinados dados inéditos do projeto, que se referem à pergunta assinalada, documentados nas 38 localidades pertencentes à rede de pontos no estado de São Paulo e em mais dez cidades situadas na área limítrofe com a fronteira paulista (Mato Grosso do Sul, Minas Gerais, Paraná e Rio de Janeiro), denominadas neste texto como área de controle.

O universo da pesquisa foi formado por 196 informantes, sendo quatro pertencentes a cada ponto linguístico situado no interior dos estados e oito na capital paulista. Quanto ao perfil dos entrevistados, foram consideradas as seguintes características: i) sexos: masculino/feminino; ii) faixas etárias I: 18-30 e II: 50-65; iii) graus de escolaridade: universitário e fundamental (capital) e ensino fundamental completo nas demais localidades investigadas.

Este trabalho utiliza pressupostos teóricos da Dialetologia (CARDOSO, 2010), da Lexicologia (BIDERMAN, 1978), da Semântica (COSERIU, 1979) e da Etnolinguística (SAPIR, 1969) e analisa as denominações produtivas, além de discutir as possíveis motivações de seu uso. A análise prevê ainda os seguintes procedimentos: i) comparar os dados com outros estudos concluídos no estado de São Paulo e na área de controle com o intuito de verificar semelhanças e diferenças em termos de nomeações da brincadeira "amarelinha"; ii) examinar, com base nos dados investigados, a inter-relação entre léxico, cultura e história social que singulariza o estado de São Paulo e iii) traçar possíveis áreas dialetais a partir das variantes lexicais documentadas.

A pergunta foi eleita como objeto de análise tendo em vista a relevância dos divertimentos infantis no cotidiano das pessoas, a popularidade da "amarelinha" como um tipo de recreação tradicional e o baixo número de abstenção de respostas na etapa da recolha dos dados por parte dos pesquisadores do Projeto ALiB.

3 A área de controle é um procedimento metodológico proposto por Ribeiro (2012) na tese de doutorado intitulada: Brinquedos e brincadeiras infantis na área do falar baiano. Neste artigo, a adoção da área de controle refere-se ao conceito utilizado, pois a aplicação foi reformulada. o exame dos dados documentados nessa área tem como objetivo verificar o comportamento linguístico dos falantes de espaços geográficos próximos à região selecionada para a pesquisa, no caso o estado de São Paulo, no que se refere às respostas fornecidas para a pergunta em análise. 
A brincadeira contemplada pela pergunta 167/QSL/ALiB - "como se chama a brincadeira em que as crianças riscam uma figura no chão, formada por quadrados numerados, jogam uma pedrinha (mímica) e vão pulando com uma perna só?" (COMITÊ NACIONAL DO PROJETO ALiB, 2001, p. 35), conhecida popularmente como "amarelinha", é uma recreação tradicional, com registros desde a Grécia antiga e Oriente (KISHIMOTO, 2015). No Brasil, ela é bastante popular, sobretudo considerando-se as últimas gerações, e possui variados formatos.

Meirelles (2007, p. 33), por exemplo, pondera que ela é:

[...] Provavelmente, uma das brincadeiras mais conhecidas. Existe uma variedade enorme de desenhos e regras espalhados pelos pés de crianças no mundo inteiro. São tantas as culturas que pulam há séculos nesses tradicionais desenhos, que dá até para nos convencermos de que se trata de gestos necessários à infância, um verdadeiro símbolo infantil.

Essa popularidade parece refletir-se no ato de nomeá-la, pois, ao analisar os dados referentes à questão 167/QSL/ALiB, verifica-se que a pergunta foi bastante produtiva, registrando 13 denominações como resposta, além de oito ocorrências únicas, ${ }^{4}$ num universo de 186 registros.

Considerando o alto número de variantes lexicais documentadas, foram realizados alguns agrupamentos, que resultaram em quatro itens lexicais listados de acordo com a produtividade: amarelinha, marelinha, maré e pula-pula. Além dessas, ocorreram sete respostas reunidas a outras denominações. No Quadro 1, a seguir, apresentam-se as variantes lexicais e os respectivos agrupamentos.

4 A expressão ocorrência única é utilizada quando apenas um informante indica uma resposta que não é informada por nenhum outro entrevistado, considerando todos os pontos de inquéritos investigados. 
Quadro 1. Agrupamentos de variantes lexicais para "a brincadeira em que as crianças riscam uma figura no chão, formada por quadrados numerados, jogam uma pedrinha (mímica) e vão pulando com uma perna só" (Banco de Dados do Projeto ALiB, 2018)

\begin{tabular}{|l|l|}
\hline Variantes lexicais & Agrupamentos \\
\hline Amarelinha & Amarelinha, amarelinhas, pula de amarelinha, amarelim \\
\hline Marelinha & Marelinha, marelim \\
\hline Maré & maré, pula maré, jogá maré, a maré, brinca de marezinho, \\
\hline Pula-pula & Pula-pula, jogo de pula-pula \\
\hline $\begin{array}{l}\text { Outras } \\
\text { denominações }\end{array}$ & $\begin{array}{l}\text { Quadradinho, cruzadinha, pedrinha, marrequinha, pula balé, malha, } \\
\text { alerta-cor }\end{array}$ \\
\hline
\end{tabular}

Fonte: Elaboração própria.

Os agrupamentos, em sua maioria, obedeceram a critérios lexicais, fonéticos, morfológicos e associativos. Quanto à denominação, os termos amarelinha e marelinha, foram separados apenas na discussão das variáveis sociais (diatópica, diageracional e diassexual) devido à alta produtividade que obtiveram individualmente e pelo fato de terem destaque na fala de informantes com características distintas.

Na sequência, discutem-se os dados sobre a produtividade das variantes cartografadas, considerando-se as áreas investigadas como blocos (estado de São Paulo ${ }^{5}$ e área de controle).

\section{Amarelinha: produtividade das variantes cartografadas}

Nas localidades investigadas, houve a predominância da variante amarelinha como denominação para a brincadeira em questão, tanto no estado de São Paulo quanto na área de controle. Ao observar apenas os dados paulistanos, informa-se que na capital apenas um informante não utilizou esse designativo ${ }^{6}$. No interior do estado, o quantitativo é um pouco menor, porém bastante expressivo. No Gráfico 1, é possível visualizar os

5 Considerando apenas as respostas fornecidas pelos informantes da capital paulista, é possível afirmar a predominância de amarelinha com o valor percentual de $87,5 \%$ das respostas obtidas, concorrendo apenas com a ocorrência única marelinha (informante do sexo masculino, faixa etária II) $\operatorname{com} 12,5 \%$.

6 A resposta indicada pelo informante foi marelinha. 
valores percentuais de ocorrência das variantes lexicais em análise a partir das respostas válidas para a questão 167/QSL/ALiB nos pontos linguísticos do interior de São Paulo.

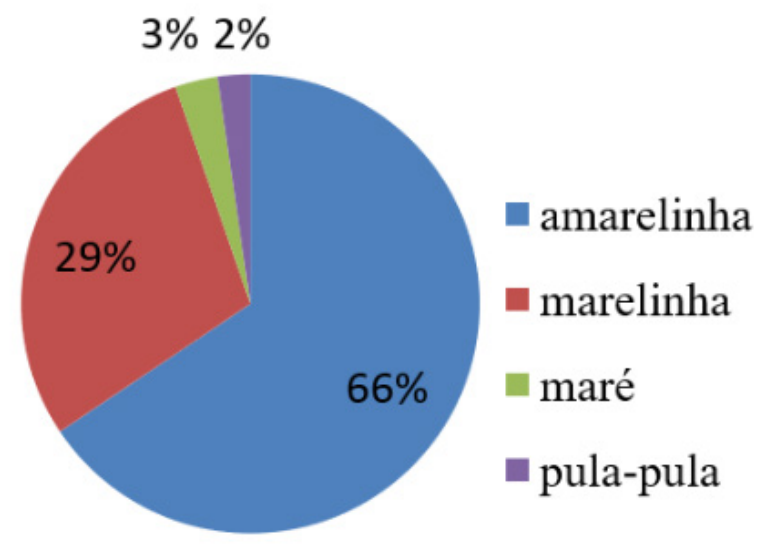

Gráfico 1. Denominações para amarelinha e respectivo índice de ocorrência no interior de São Paulo

Fonte: Banco de Dados do Projeto ALiB (2018).

Conforme os dados do Gráfico 1, nota-se que a maioria da população do interior do estado (66\%) optou pelo uso da unidade lexical amarelinha, seguida da denominação marelinha (29\%). As demais respostas receberam valores percentuais muito próximos e baixos.

Por sua vez, os dados oriundos das localidades da área de controle demonstram mudanças quanto à produtividade das respostas obtidas, apesar de amarelinha ainda ser a variante mais recorrente, com $52,6 \%$ das ocorrências. A segunda mais produtiva é maré (29\%), seguida de marelinha (18,40\%).

Genericamente, os dados obtidos na área de controle não evidenciam grandes mudanças no que tange à predominância de amarelinha na maioria dos estados: é o que atesta o Gráfico 2: 


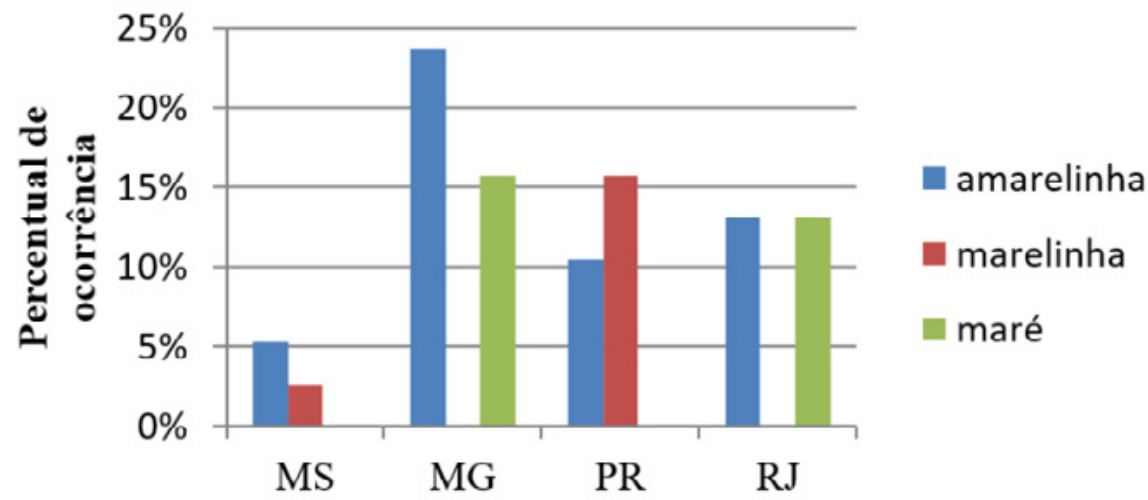

Gráfico 2. Produtividade das denominações para amarelinha e respectivo índice de ocorrência segundo a Unidade da Federação/área de controle

Fonte: Banco de Dados do Projeto ALiB (2018).

As informações do Gráfico 2 comprovam que a unidade lexical amarelinha se mantém como a variante mais produtiva, haja vista a totalidade das respostas da área de controle. Por sua vez, o exame dos dados dos pontos de inquérito selecionados dos estados vizinhos demonstra que apenas no Paraná marelinha é a forma mais produtiva do que amarelinha.

De modo geral, as duas respostas mais produtivas de cada estado apontam para uma subdivisão. No caso, seriam agrupados: i) MS e PR, com as ocorrências de amarelinha e marelinha e ii) MG e RJ, com amarelinha e maré. Tendo em vista essa subdivisão e a melhor visualização dos dados paulistas, é possível verificar as duas cartas lexicais produzidas acerca dessa pergunta (Anexo 1 - carta 7a: Denominações para amarelinha/São Paulo (interior) - e Anexo 2 - carta 7b: Denominações para amarelinha/área de controle).

Após o estudo das cartas produzidas com os dados referentes à questão 167/QSL/ ALiB, são discutidos os aspectos diatópicos referentes às denominações obtidas, com destaque para as unidades léxicas cartografadas.

\section{Análise diatópica das denominações para "amarelinha" cartografadas}

A análise das denominações fornecidas pelos informantes é apresentada de acordo com a produtividade de cada variante em ordem decrescente, priorizando aquelas obtidas no estado de São Paulo. 


\subsection{Amarelinha/marelinha}

O item lexical amarelinha teve alta produtividade em toda a área investigada neste estudo, atingindo um maior número de ocorrências nas mesorregiões de Itapetininga, Metropolitana de São Paulo e São José do Rio Preto. Não foi registrado apenas em um ponto de inquérito do estado de São Paulo: Presidente Epitácio (Ponto 161).?

No que diz respeito à denominação marelinha, esta foi documentada em boa parte do estado, embora não tenha obtido registro nas seguintes mesorregiões: São José do Rio Preto, Araraquara, Assis, Itapetininga, Litoral Sul Paulista e Vale do Paraíba.

Haja vista a área de controle, verifica-se que: i) no Paraná e no Mato Grosso do Sul, foram documentadas as denominações amarelinha ${ }^{8}$ e marelinha ${ }^{9}$ e ii) no estado de Minas Gerais e Rio de Janeiro, não há a menção a marelinha como resposta em nenhuma localidade.

Quanto aos aspectos diageracionais e diassexuais, pontua-se que a forma amarelinha foi fornecida por um número maior de informantes do sexo feminino (63\%) em relação aos do sexo masculino (37\%). Em relação à idade, foi mais produtiva entre os informantes mais jovens (62\%), como atesta o Gráfico 3, que indica seus valores percentuais de acordo com os diferentes perfis:

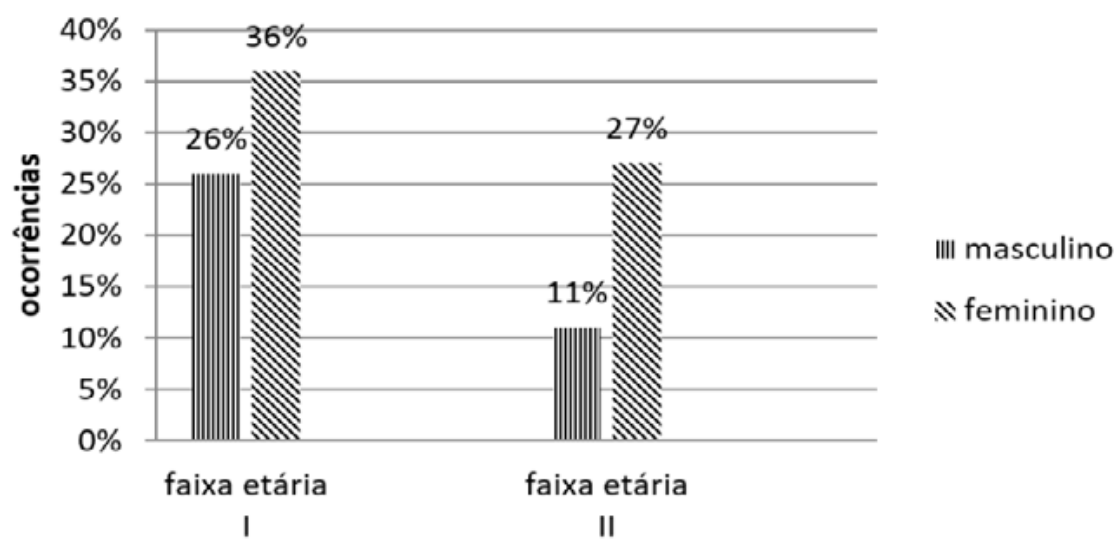

Gráfico 3. Realização de amarelinha considerando as dimensões diassexual e diageracional

Fonte: Banco de Dados do Projeto ALiB (2018).

\footnotetext{
7 A variante marelinha foi a única resposta fornecida por todos os informantes de Presidente Epitácio.

$8 \mathrm{Na}$ área de controle, amarelinha não foi registrada apenas em Adrianópolis (216) e em Barra Mansa (205).

9 No estado do Paraná, apenas a localidade de Tomazina (211) não forneceu marelinha como resposta.
} 
De modo inverso, a denominação marelinha apresenta predominância na fala dos informantes do sexo masculino, com 59\% das ocorrências para essa variável e $41 \%$ referentes ao sexo feminino. No que tange às idades, a resposta predomina na faixa etária II, com $57 \%$, em oposição a $43 \%$ dos informantes da faixa etária I, como pode ser verificado no Gráfico 4:

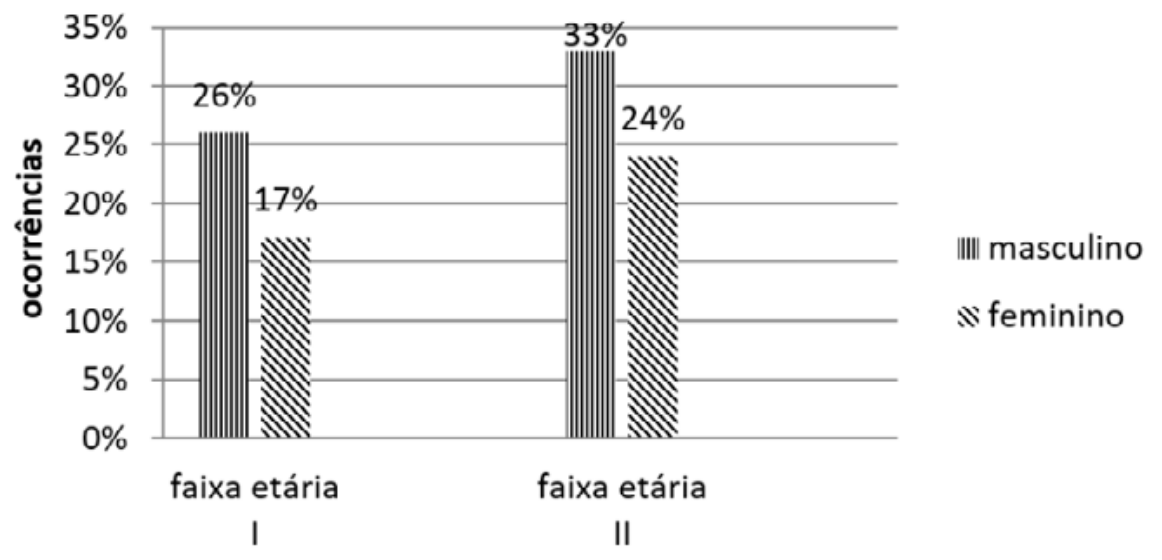

Gráfico 4. Realização de marelinha considerando as dimensões diassexual e diageracional

Fonte: Banco de Dados do Projeto ALiB (2018).

De acordo com os Gráficos 3 e 4, percebe-se que amarelinha é a variante mais produtiva entre os informantes mais jovens e do sexo feminino. Por sua vez, as ocorrências de marelinha recaem entre os informantes mais idosos e do sexo masculino, o que indica que esta pode ser uma forma mais antiga em uso entre esses falantes. A seguir, examinase a disposição dos dados referentes à unidade léxica maré.

\subsection{Maré}

A unidade lexical maré foi uma denominação com produtividade mais restrita, sendo documentada apenas em duas localidades paulistas: Ribeirão Preto (157) e Itapetininga (177). Já na área de controle, foi registrada em todos os pontos de inquérito do estado de Minas Gerais, investigados neste estudo, e na localidade de Barra Mansa, no Rio de Janeiro. ${ }^{10}$

10 Destacam-se os registros de maré em Barra Mansa (205), estado do Rio de Janeiro, em que foi a única denominação fornecida por três informantes. 
Em relação aos aspectos diassexuais e diageracionais, maré foi mais produtiva entre os informantes mais idosos (93\%) e do sexo feminino (60\%), como atesta o Gráfico 5 :

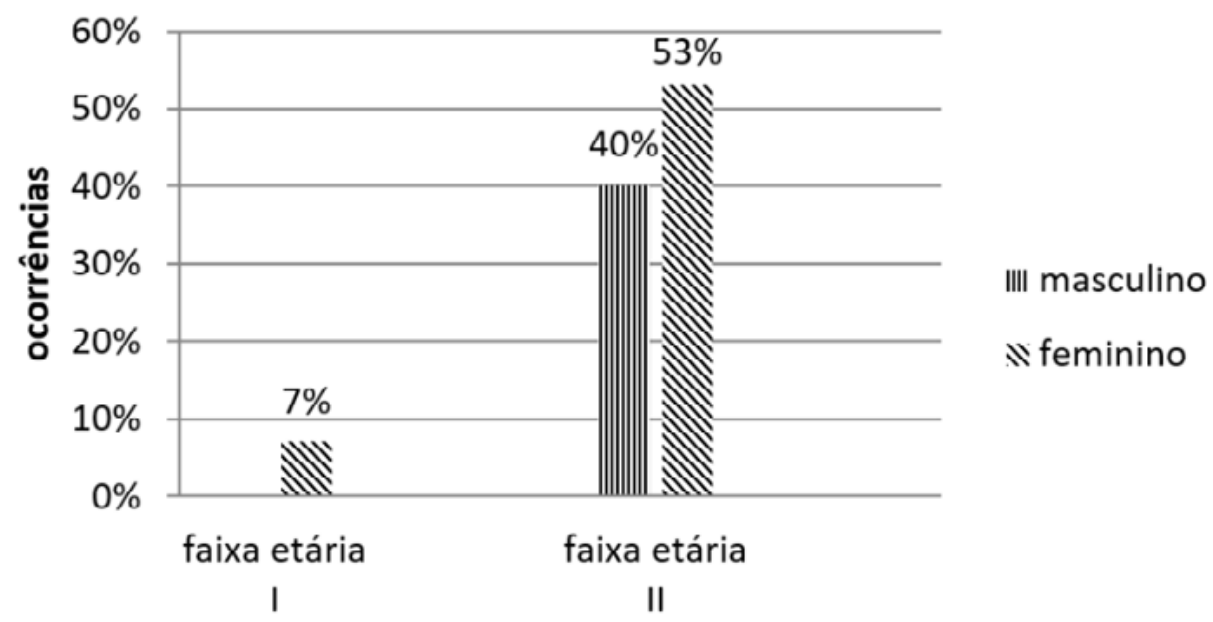

Gráfico 5. Realização de maré considerando as dimensões diassexual e diageracional

Fonte: Banco de Dados do Projeto ALiB (2018).

A verificação do Gráfico 5 mostra, como destaque, que a variante maré é majoritariamente utilizada por falantes da faixa etária II, com exceção de duas ocorrências na faixa etária I. Essa constatação pode ser confirmada pelo seguinte comentário:

INF.- É... amarelinha?/INQ.- Como é que é? /INF.- Eh, a gente falava "brincá de a... maré, maré" / INQ.- Maré? /INF.- "Jogá maré". Eles falam agora amarelinha né, na minha época era jogá maré (Ribeirão Preto - ponto 157 - informante do sexo masculino, faixa etária II).

Essa preferência pelo item lexical maré por parte da faixa etária Il possivelmente representa uma forma de uso antiga que se mantém na norma lexical do grupo assinalado. $\mathrm{Na}$ sequência, discutem-se os dados sobre o item lexical pula-pula.

\subsection{Pula-pula}

O item lexical pula-pula teve baixa produtividade, tendo sido registrado como ocorrência única nas localidades paulistas de Andradina (155), Araçatuba (156) e Caraguatatuba (180). Já na área de controle, foi fornecido apenas por um informante da cidade mineira 
de Campina Verde (137). Tendo em conta o perfil do informante, ${ }^{11}$ pula-pula foi indicado unicamente por informantes pertencentes à faixa etária II do sexo masculino. Na próxima seção, discutem-se os dados referentes às ocorrências únicas.

\title{
2.4 Outras denominações
}

Como outras denominações, foram obtidas respostas com duas semelhanças básicas: serem proferidas por informantes do sexo masculino e com grau de escolaridade fundamental. É possível dividir esses registros em dois grupos, de acordo com as idades: i) faixa etária I, com a indicação das denominações: cruzadinha (Adrianópolis/216) e malha (Ribeira/185) e ii) faixa etária II, com as respostas: pedrinha (Lins/158), quadradinho (Botucatu/171), marrequinha (Registro/186), pula-balé (Poços de Caldas-MG/147), alertacor (Barra Mansa-RJ/205). O fato de essas denominações recaírem na fala de informantes do sexo masculino aponta para uma menor afinidade ou contato por parte desses entrevistados com a brincadeira em questão. Essa possibilidade se acentua no fato de que apenas duas mulheres deixaram de fornecer resposta para a pergunta e no fato de haver alguns fragmentos de entrevistas, em que determinados informantes indicaram a "amarelinha" como uma "brincadeira de menina", como se lê na sequência:

\begin{abstract}
INF. O nome eu não sei... a pessoa faz, isso é muito menina também que brinca, que faz tipo quatro quadrinho aqui, põe dois no meio e tem que ir pulando. Se você errar, daí é isso... o nome, que eu já vi muitas meninas brincar, é essa. Agora sumiu que quase ninguém brinca (Barra Mansa/ MG - ponto 205, informante do sexo masculino, faixa etária I).
\end{abstract}

A seguir, são discutidas as ocorrências das denominações analisadas em outros trabalhos dialetais. Inicialmente, em âmbito nacional, e, na sequência, nos pontos de inquérito no estado de São Paulo e/ou área de controle.

\section{Cotejo com resultados de outras pesquisas geolinguísticas na área investigada}

Haja vista os dados nacionais mapeados pelo Atlas Linguístico do Brasil (CARDOSO et al., 2014) relativos às capitais brasileiras na carta L23 (CARDOSO et al., 2014), verificase que amarelinha é a variante mais produtiva como denominação para o referente expresso na pergunta 167 (QSL/ALiB). Nessa mesma carta, é possível observar que, nas capitais relativas aos estados da área de controle, a forma amarelinha ocorre com mais

11 Não foi produzido gráfico para visualizar o fenômeno devido à baixa produtividade da denominação. 
de uma denominação: i) no Paraná, com a resposta caracol'12 e ii) em Minas Gerais, com a denominação maré.

Os dados cartografados em outros trabalhos dialetais com pontos de inquérito no estado de São Paulo ou localidades investigadas da área de controle permitiram produzir o Quadro 2, que indica as variantes registradas nesses estudos/atlas:

Quadro 2. Registro de denominações para a amarelinha em outras pesquisas geolinguísticas - São Paulo e área de controle

\begin{tabular}{|c|c|c|c|c|}
\hline Trabalhos/atlas & amarelinha & maré & pula-pula & $\begin{array}{c}\text { Outras denominações } \\
\text { registradas na carta }{ }^{\mathbf{3}}\end{array}$ \\
\hline $\begin{array}{c}\text { Atlas Linguístico do Paraná - carta } \\
91\end{array}$ & $X$ & & $\begin{array}{c}\text { caracol, quadrinho(a), } \\
\text { boneco }\end{array}$ \\
\hline $\begin{array}{c}\text { Atlas Linguístico Topodinânimo do } \\
\text { Oeste de São Paulo - carta 087 } \\
\text { (SANTOS-IKEUCHI, 2014, p. 309) }\end{array}$ & $X$ & $X 94$, p. 205) & & \\
\hline $\begin{array}{c}\text { Léxico dos brinquedos e } \\
\text { brincadeiras em Minas Gerais - } \\
\text { carta 10 } \\
\text { (D’ANUNCIAÇÃO, 2016, p. 81) }\end{array}$ & $X$ & $X$ & $X$ & maê, baliza, macaco \\
\hline $\begin{array}{c}\text { Falar fluminense } \\
\text { (SANTOS, 2016, p. 179) }\end{array}$ & $X$ & $X$ & $X$ & pé-pé, maê, baliza \\
\hline
\end{tabular}

Fonte: Elaboração própria. ${ }^{14}$

Nota-se a superioridade da denominação amarelinha, que está presente em todos os trabalhos elencados. Além disso, sua importância também se revela pelo fato de ser a denominação mais produtiva em todas as pesquisas citadas.

Quanto aos demais designativos documentados nos trabalhos elencados, lê-se que, no Atlas Linguístico do Paraná - ALPR (AGUILERA, 1994), há o acréscimo de caracol, quadrinho(a) e boneco. No Atlas Linguístico Topodinâmico do Oeste de São Paulo -

12 Essa denominação foi registrada na carta $L 23$ como outras. Porém, ao verificar a carta L23d (CARDOSO et al., 2014), específica da região Sul, há sua indicação.

13 As denominações foram indicadas em ordem decrescente de produtividade.

14 Com base nos atlas/trabalhos referenciados. 
ALTOSP (SANTOS-IKEUCHI, 2014), por seu turno, amarelinha ${ }^{15}$ é a única denominação cartografada, e com alta produtividade, pois deixou de ser indicada apenas por três informantes em um universo de 32 entrevistados.

No Mato Grosso do Sul, bem como em Minas Gerais, informa-se que os atlas estaduais não contêm carta que se refira à brincadeira em questão. No caso de dados mineiros, recupera-se o estudo produzido como monografia na Universidade Federal da Bahia, por Eliana Souza D’Anunciação: "Registrando o léxico dos brinquedos e brincadeiras infantis em Minas Gerais"16 (2016), que apresenta a cartografação das denominações: maré, maê, pula-pula, baliza e macaco. Observa-se, à exceção de macaco, que os demais nomes também são indicados na Dissertação de Mestrado defendida na Universidade Federal da Bahia por Leandro Almeida dos Santos, Brincando pelos caminhos do falar fluminense (2016), com o acréscimo apenas de pé-pé.

De modo geral, além da importância de amarelinha, verifica-se que as denominações registradas nos estados vizinhos reforçam a presença de maré nos estados de Minas Gerais e do Rio de Janeiro.

Na sequência, examinam-se as variantes produtivas para "amarelinha" sob o viés léxicosemântico.

\section{Análise léxico-semântica}

Para fins de análise semântica, as respostas fornecidas pelos informantes foram agrupadas seguindo alguns processos associativos realizados quando da obtenção das denominações. Para tanto, priorizou-se o conteúdo expresso na pergunta analisada. Ademais, foi considerado o sema comum em um conjunto de respostas ou alguma possibilidade de combinação entre as denominações obtidas. Veja o Quadro 3, em que se pode verificar as associações realizadas e consequentemente as denominações agrupadas:

15 No ALPR e no ALTOSP, acredita-se que tenha havido a junção das respostas amarelinha e marelinha devido a algumas notas registradas nas respectivas cartas. Esse dado, todavia, auxilia na compreensão da permanência da denominação marelinha nos pontos linguísticos do Paraná e em São Paulo nas coletas de dados do Projeto ALiB, discutidos neste estudo.

16 Nessa monografia, o número de ocorrências de marelinha foi pouco significativo, pois "[...] foi registrado apenas em um informante de Patos de Minas, nas demais localidades só documentamos a presença da lexia amarelinha" (D'ANUNCIAÇÃO, 2016, p. 77). Logo, também houve a junção entre as unidades léxicas (amarelinha e marelinha) no referido trabalho. 
Quadro 3. Distribuição das denominações para "amarelinha" segundo os traços semânticos (Banco de Dados do Projeto ALiB, 2018).

\begin{tabular}{|c|c|c|c|}
\hline Característica & $\begin{array}{c}\text { Processos } \\
\text { associativos }\end{array}$ & Descrição & Denominações \\
\hline \multirow{4}{*}{$\begin{array}{c}\text { Traços } \\
\text { semânticos/ } \\
\text { texto da } \\
\text { pergunta }\end{array}$} & Brincadeira & $\begin{array}{c}\text { Nomes de } \\
\text { brincadeiras }\end{array}$ & $\begin{array}{c}\text { amarelinha, pula-pula } \\
\text { marelinha, maré }\end{array}$ \\
\cline { 2 - 4 } & $\begin{array}{c}\text { Jigura riscada no chão } \\
\text { com números }\end{array}$ & $\begin{array}{c}\text { Formas geométricas } \\
\text { do desenho }\end{array}$ & quadradinho, cruzadinha \\
\cline { 2 - 4 } & $\begin{array}{c}\text { Pular comessar ulgo } \\
\text { só }\end{array}$ & $\begin{array}{c}\text { Associação com } \\
\text { outras brincadeiras de } \\
\text { arremesso }\end{array}$ & $\begin{array}{c}\text { marrequinha, malha, } \\
\text { alerta-cor }\end{array}$ \\
\cline { 2 - 4 } & Ação de pular & pula balé, pula-pula. \\
\hline
\end{tabular}

Fonte: Elaboração própria.

Os dados do Quadro 3 permitem verificar que o primeiro agrupamento foi realizado a partir das denominações que se referem à brincadeira diretamente relacionada aos nomes de entretenimentos infantis: amarelinha, marelinha, maré e pula-pula. Já no segundo, as denominações estão relacionadas às formas dos desenhos no chão ou à imagem que possa ter sido gerada na memória dos falantes; por seu turno, o terceiro agrupamento congrega respostas provavelmente indicadas pela ação de jogar algum objeto e, no quarto grupo, pelo modo de pular no momento de executar a brincadeira. ${ }^{17}$

No processo de associação, a consulta a dicionários de língua portuguesa representativos de diferentes estágios da história da língua foi fundamental. Considerando os séculos XVIII e XIX, foram consultados os dicionários de Bluteau (1712-1728), Moraes Silva (1813) e Silva Pinto (1832); verifica-se que apenas a unidade léxica maré está registrada nesses dicionários, porém com definição distinta de recreação infantil. Já nos dicionários do século XX, ilustrados pelo Quadro 4, há a documentação das variantes lexicais dicionarizadas nas obras contemporâneas com a acepção da brincadeira solicitada (QSL 157/ALiB) ou ainda como possível recreação infantil. Destacam-se, nas acepções, elementos que possam ter motivado as respostas obtidas.

17 Neste artigo, por não ser objeto de estudo, não foram discutidas as relações estabelecidas nos demais agrupamentos. 
Quadro 4. Dicionarização das unidades léxicas que nomeiam "amarelinha".

\begin{tabular}{|c|c|c|c|}
\hline $\begin{array}{l}\text { Dicionários/ } \\
\text { Item lexical }\end{array}$ & Houaiss; Villar (2002) & Aulete (2006) & Ferreira (2010) \\
\hline Amarelinha & $\begin{array}{l}\text { s.f Rubrica: Ludologia. } \\
\text { Regionalismo: Brasil. } \\
\text { (brincadeira infantil } \\
\text { que consiste em saltar, } \\
\text { com apoio numa só } \\
\text { perna, casa a casa de } \\
\text { uma figura riscada no } \\
\text { chão, após jogar uma } \\
\text { pequena pedra achatada, } \\
\text { ou objeto semelhante, } \\
\text { em direção a cada uma } \\
\text { das casas (quadrado), } \\
\text { sequencialmente, pulando } \\
\text { a que contém a pedra } \\
\text { ou objeto. ETIM. orig. } \\
\text { contrv. SIN/VAR academia, } \\
\text { macaca, macaco, maré, } \\
\text { marela, sapata. }\end{array}$ & $\begin{array}{l}\text { Bras. Lud. Jogo infantil } \\
\text { que consiste em pular, } \\
\text { num pé só, uma série de } \\
\text { casas riscadas no chão. } \\
\text { [F.: Do fr. marelle, posv.] }\end{array}$ & $\begin{array}{l}\text { S.f. Bras. Jogo } \\
\text { infantil que consiste } \\
\text { em pular num pé } \\
\text { só sobre casas } \\
\text { riscadas no chão, } \\
\text { exceto aquela em } \\
\text { que cai a pedra que } \\
\text { marca a progressão } \\
\text { do brincante; } \\
\text { macaco, (RS) } \\
\text { sapata. }\end{array}$ \\
\hline Maré & $\begin{array}{l}\text { s.f. LUD MG GO m.q. } \\
\text { AMARELINHA. ETIM prov } \\
\text { alt de marela. SIN/VAR ver } \\
\text { sinonímia de amarelinha. }\end{array}$ & & \\
\hline pula-pula ${ }^{18}$ & & $\begin{array}{l}\text { Lud. Qualquer brinquedo } \\
\text { próprio para pular, } \\
\text { como cama elástica ou } \\
\text { inflável. }\end{array}$ & \\
\hline
\end{tabular}

Fonte: Elaboração própria. ${ }^{19}$

O Quadro 4 mostra que as denominações amarelinha e maré fazem referência explícita à brincadeira solicitada na questão 167/QSL/ALiB. Já pula-pula pode ser compreendida como resposta válida, posto que a brincadeira em questão se refere a qualquer brinquedo

18 Nos dicionários consultados anteriores ao século XX, não há o registro de pula-pula. No verbete referente ao verbo pular, também não há referência ao entretenimento referido na questão.

19 Com base nos dados extraídos dos dicionários referenciados. 
próprio para pular. Ou seja, possivelmente, o informante estabeleceu uma relação de comparação entre a definição e a pergunta, com a possibilidade de ter considerado os traçados no chão como uma brincadeira.

Pelo Quadro 4, ainda é possível observar, na definição indicada pelo dicionário Aulete (2006), a informação da origem da unidade léxica amarelinha como procedente de "marelle" (francês).

Barbeiro e Isquerdo (2007, p. 114) acrescem às informações já listadas o fato de que "[...] amarelinha se constitui em forma inovadora do português do século XVIII, um empréstimo do francês na variante europeia, que veio para o Brasil com a Família Real".

Câmara Cascudo (2012, p. 06-07) também salienta a origem francesa da "amarelinha" no Dicionário do Folclore Brasileiro quando define cademia:

A academia ou cademia é conhecida como amarelinha ou marelinha no Rio de Janeiro, maré em Minas Gerais, e recentemente avião, no Rio Grande do Norte. Na Bahia dizem pular macaco. Em Portugal: jogo da macaca ou pular macaca, jogar macaca (Norte). Pela Extremadura é jogo do homem. Na Espanha: cuadrillo. No Chile é rayuela, assim como no Peru. Na Colômbia é coroza ou golosa. Na Espanha denominam-na também infernáculo, reina mora, pata coja. No Chile a conhecem também, e mais popularmente, por luche. $\mathrm{Na}$ França é marelle de onde provém os nossos amarelinha e maré.

Verifica-se, pelo fragmento do Dicionário do Folclore (CÂMARA CASCUDO, 2012), a presença do entretenimento em diferentes países, sendo marcado pela diversidade de suas denominações.

Diante das informações elencadas, nota-se que amarelinha é bastante representativa para a brincadeira ainda existente em diferentes culturas. Essa situação também se confirma na realidade brasileira, sobretudo considerando as localidades investigadas.

\section{Considerações finais}

A produtividade e a distribuição diatópica dos dados discutidos evidenciaram que, em todas as localidades investigadas, foram documentadas denominações para a "amarelinha", o que demonstra que a brincadeira mantém-se no cotidiano dos brasileiros do Sudeste e faz parte de suas lembranças de infância, a julgar pelos nomes a ela conferidos. 
Pontua-se também que as respostas foram fornecidas por falantes das duas faixas etárias, com maior incidência entre os da faixa etária II, sobretudo entre as do sexo feminino, o que demonstra a vitalidade da brincadeira que se mantém, contemporaneamente, como atividade de recreação em ambiente escolar.

Haja vista a variante mais produtiva neste estudo, amarelinha foi documentada tanto nas localidades do estado de São Paulo quanto nas pertencentes à área de controle. Ao comparar este estudo aos demais trabalhos dialetais realizados na área investigada, a superioridade dessa denominação continua preservada: Aguilera (1994), Santos-Ikeuchi (2014), D’Anunciação (2016) e Santos (2016). Além dos textos elencados, amarelinha ainda predomina nas capitais brasileiras segundo os dados nacionais cartografados pelo Atlas Linguístico do Brasil, carta L23 (CARDOSO et al., 2014, p. 315). Recupera-se ainda a informação de que, nos trabalhos dialetais consultados, não há menção explícita sobre as ocorrências de marelinha, exceto em D’Anunciação (2016). Provavelmente, marelinha tenha sido fruto da junção de amarelinha e marelinha ou ainda não tenha tido registros significativos nos trabalhos em questão. Independente dos motivos, salienta-se que o predomínio da variante amarelinha entre os nomes atribuídos à brincadeira atesta a força da norma ${ }^{20}$ difundida pela escola.

Quanto à denominação maré27, o seu uso está mais concentrado no estado de Minas Gerais e na localidade paulista de Ribeirão Preto (157), que é próxima à fronteira MG-SP.

Ainda cabe informar que a unidade lexical pula-pula, apesar de nomear entretenimento diverso do descrito pela pergunta selecionada, foi citada como nome da brincadeira "amarelinha", uso confirmado pela insistência dos inquiridores e/ou solicitação da descrição do jogo. Além disso, D’Anunciação (2016) registrou uma ocorrência dessa variante no estado de Minas Gerais.

Para concluir, nota-se que, nos processos de nomeação da brincadeira analisada, a relação intrínseca entre o léxico e a sociedade é marcada, sobretudo, pelas seguintes situações: i) a disseminação da variante lexical amarelinha por todo o território paulista; ii) a concentração de determinadas denominações em regiões específicas da área de estudo, como é o caso de maré e iii) a preferência de perfis específicos por algumas variantes, como é o caso de pula-pula mencionada apenas pelos informantes do sexo masculino, faixa etária II. Essas considerações corroboram a afirmação de Isquerdo e Oliveira (2001, p. 9), para quem "[...] o universo lexical de um grupo sintetiza a sua maneira de ver a realidade e a forma como seus membros estruturam o mundo em que os rodeia e designam as diferentes esferas do conhecimento".

20 Entende-se norma como o "[...] sistema de realizações obrigadas, de imposições sociais e culturais, e [que] varia segundo a comunidade" (COSERIU, 1979, p. 74).

21 A resposta maré também foi registrada em Itapetininga (177). 
Em síntese, os dados demonstraram a estreita relação entre léxico e sociedade e confirmam que "[...] o léxico da língua é o que mais nitidamente reflete o ambiente físico e social dos falantes" (SAPIR, 1969, p. 45). Essa relação, neste trabalho, está evidenciada, de modo mais expressivo, na disseminação da variante lexical amarelinha em todo o território investigado, além da concentração de maré nos estados de Minas Gerais e Rio de Janeiro.

\section{REFERÊNCIAS}

AGUILERA, V. de A. Atlas Linguístico do Paraná. Curitiba: Imprensa Oficial, 1994.

AULETE, F. J. C.; VALENTE, A. L. dos S. Aulete Digital: Dicionário Contemporâneo de Língua Portuguesa. Rio de Janeiro: Lexikon Editora Digital, 2006. Disponível em: http://aulete. com.br/. Acesso em: 20 ago. 2018.

BARBEIRO, E. P.; ISQUERDO, A. N. O Atlas Linguístico do Brasil e a descrição da norma lexical regional: contribuições no campo das brincadeiras infantis. In: Encontro Anual de Iniciação Científica, 16 Anais... Londrina, 2007, Disponível em: http://www.eaic.uem.br/ artigos/CD/1221.pdf. Acesso em: 24 ago. 2011.

BIDERMAN, M. T. C. Teoria linguística: linguística quantitativa e computacional. Rio de Janeiro: LTC Ed., 1978.

BLUTEAU, R. Vocabulario portuguez \& latino: áulico, anatômico, architectonico... Coimbra: Collegio das Artes da Companhia de Jesus, 1712-1728.

CARDOSO, S. A. M. Geolinguística: Tradição e modernidade. São Paulo: Parábola, 2010.

CARDOSO, S. et al. Atlas Linguístico do Brasil. Cartas Linguísticas. v. 2. Londrina: EDUEL, 2014.

CÂMARA CASCUDO, L. Dicionário do Folclore Brasileiro. São Paulo: Editora Global, 2012.

COMITÊ NACIONAL DO PROJETO ALiB. Atlas Linguístico do Brasil: Questionários 2001. 2. ed. Londrina: Ed. UEL, 2001.

COSERIU, E. Teoria da Linguagem e Linguística Geral. Rio de Janeiro: Presença Edições, 1979. 
D'ANUNCIAÇÃO, E. S. Registrando o léxico dos brinquedos e brincadeiras infantis em Minas Gerais. 2016. Monografia (Graduação em Letras) - Instituto de Letras, Universidade Federal da Bahia, Salvador, 2016.

FERREIRA, A. B. de H. Dicionário Aurélio da Língua Portuguesa. Curitiba: Positivo, 2010.

HOUAISS, A.; VILLAR, M. de S. Dicionário eletrônico Houaiss da Língua Portuguesa. Rio de Janeiro: Editora Objetiva, 2002. 1 CD-ROM.

ISQUERDO, A. N.; OlIVEIRA, A. M. P. P. de. Apresentação. In: OLIVEIRA, A. M. P. P. de.; ISQUERDO, A. N. (org.). As Ciências do Léxico. Lexicologia, Lexicografia e Terminologia. 2. ed. Campo Grande: Editora UFMS, 2001. p. 9-11.

ISQUERDO, A. N. Lexicografia e Geolinguística: Interfaces. In: MARTINS, E. S.; CANO, W. M.; FILHO, W. B. M. (org.). Léxico e Morfofonologia: perspectivas e análises. Uberlândia: EDUFU, 2006. p. 113-134.

KISHIMOTO, T. M. O jogo e a educação infantil. São Paulo: Cengage Learning, 2015.

MEIRELLES, R. Giramundo e outros brinquedos e brincadeiras dos meninos do Brasil. 3. ed. São Paulo: Editora Terceiro Nome, 2007.

RIBEIRO, S. S. C. Brinquedos e brincadeiras infantis na área do Falar Baiano. 2012. Tese (Doutorado em Letras) - Instituto de Letras, Universidade Federal da Bahia, Salvador, 2012.

SANTOS-IKEUCHI, A. C. dos. Atlas Linguístico Topodinâmico do Oeste de São Paulo. 2014. Dissertação (Mestrado em Estudos da Linguagem) - Centro de Letras e Ciências Humanas, Universidade Estadual de Londrina, Londrina, 2014.

SANTOS, L. A. dos. Brincando pelos caminhos do Falar Fluminense. 2016. Dissertação (Mestrado em Língua e Cultura) - Instituto de Letras, Universidade Federal da Bahia, Salvador, 2016.

SAPIR, E. Linguística como ciência. Rio de Janeiro: Ed. Livraria Acadêmica, 1969.

SILVA, A. M. Diccionario da lingua portugueza. 2. v. Rio de Janeiro: Francisco Alves, 1922. Fac-símile da segunda edição. Lisboa: Typographia Lacérdina, 1813. 
SILVA PINTO, L. M. da S. Diccionario da Lingua Brasileira por Luiz Maria da Silva Pinto, natural da Provincia de Goyaz. Na Typographia de Silva, 1832. Disponível em: http://www. brasiliana.usp.br/dicionario/edicao/1. Acesso em: 21 abr. 2017. 


\section{ANEXO 1}

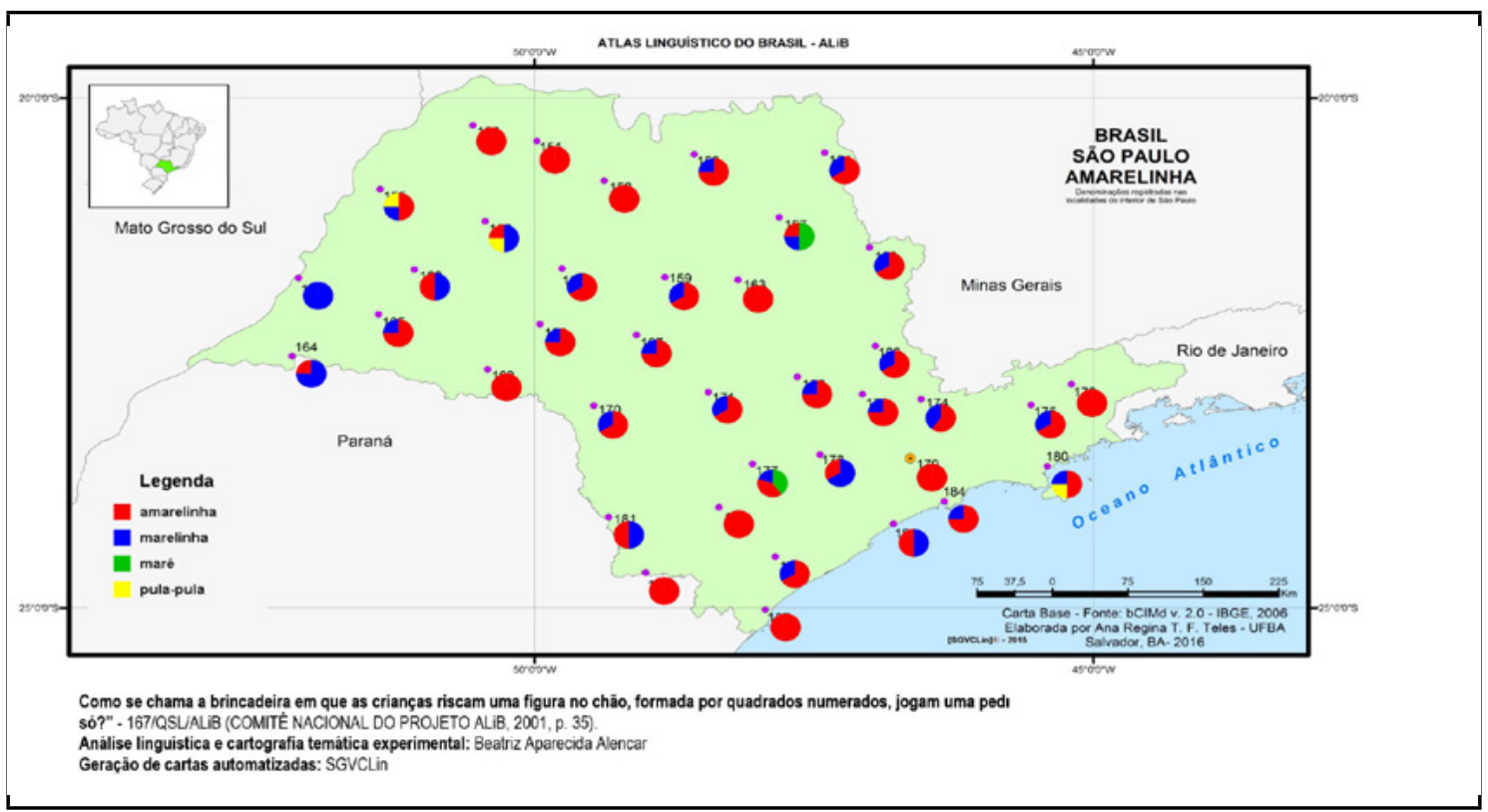

ANEXO 2

Carta 07b - Denominações para amarelinha na área de controle

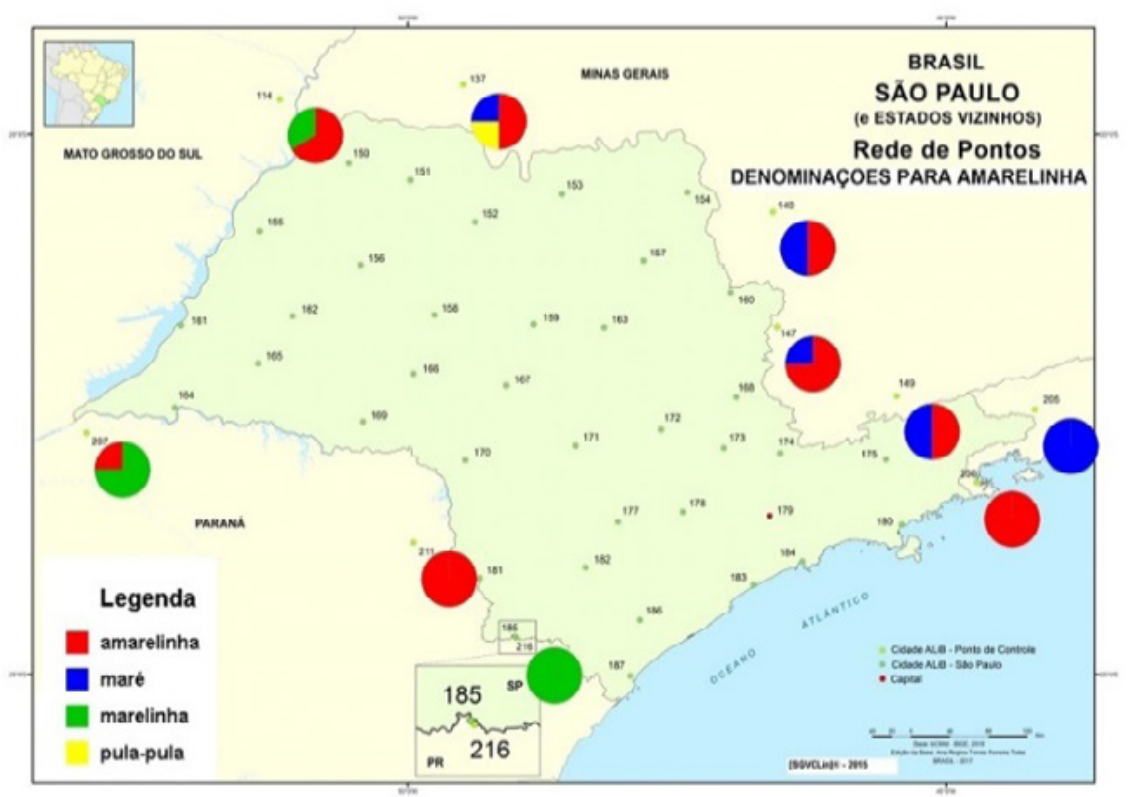

Como se chama a brincadeira em que as crianças riscam uma figura no chăo, formada por quadrados numerados, jogam uma pedrinha (mímica) e väo pulando com uma perna só? Análise lin guistica e o artografia tem átic a experim ental: Beatriz Aparecida Alencar Geração de cartas autom atizadas: SGVCLin

Fonte: Questionário do ALiB - QSL 167 